\title{
Ketajaman Klinis dalam Mendiagnosis Bising Inosen
}

\author{
Albert Daniel Solang, Najib Advani, I Boediman
}

Latar belakang. Bising inosen adalah bising yang tidak berhubungan dengan kelainan organik atau kelainan struktural jantung. Kepustakaan menyebutkan bising inosen ditemukan pada $50 \%$ populasi anak sehat. Bising ini tidak bersifat patologis tetapi sering disalahartikan sebagai bising organik, sehingga dilakukan berbagai pemeriksaan penunjang yang mahal yang sebenarnya tidak diperlukan. Ketajaman klinis seorang dokter anak dalam mendiagnosis bising inosen sangat penting untuk mengatasi biaya tinggi dan rasa kecemasan orang tua terhadap kondisi anak. Ketajaman klinis ini dapat diperoleh dengan pengalaman dan pelatihan khusus pengenalan bising jantung pada anak.

Tujuan. Membandingkan sensitivitas dan spesifitas pemeriksaan fisis dengan pemeriksaan ekokardiografi (sebagai baku emas) dalam mendiagnosis bising inosen.

Metode dan subyek penelitian. Desain penelitian adalah uji diagnostik. Populasi terjangkau pasien berusia 0 bulan-12 tahun yang berobat di Poliklinik Anak Umum RS Dr. Cipto Mangunkusumo dari tanggal 1 Agustus sampai 31 Oktober 2005. Populasi target adalah pasien dengan bising jantung tanpa sianosis. Baku emas ekokardiografi dilakukan pada semua pasien dengan bising jantung untuk mengkonfirmasi hasil pemeriksaan fisis.

Hasil. Sensitivitas diagnosis bising inosen berdasarkan pemeriksaan fisis oleh peneliti adalah $97 \%$ dan spesifisitas $50 \%$. Nilai duga positif adalah $91 \%$ dan nilai duga negatif $75 \%$. Rasio kemungkinan untuk hasil positif adalah 1,94 dan hasil negatif adalah 0,6 (hasil uji sedang).

Kesimpulan. Pemeriksaan fisis oleh peneliti yang telah mendapat pelatihan khusus pengenalan bising jantung, cukup dapat dipercaya sehingga dapat menurunkan keharusan pemeriksaan ekokardiografi yang mahal. Pelatihan berkala mengenal jenis-jenis bising jantung pada anak bagi peserta Program Dokter Spesialis Anak (PPDS) 1 Ilmu Kesehatan Anak dan dokter spesialis anak sebaiknya dilakukan untuk menambah kompetensi dalam mendiagnosis bising inosen dan menghindari biaya tinggi pemeriksaan penunjang.

Kata kunci: bising inosen, pemeriksaan fisis, ekokardiografi, anak.

\footnotetext{
Alamat korespondensi:

Dr. Najib Advani, Sp.A (K). Divisi Kardiologi Departemen Ilmu Kesehatan Anak FKUI-RSCM, Jl. Salemba 6, Jakarta 10430. Tel. 314 7342, 315 5742, Fax. 3907743.
}

Dr. Albert Daniel Solang PPDS IKA FKUI Jakarta epustakaan menyebutkan bising jantung
terdengar pada sekitar $50 \%$ populasi anak
dan merupakan alasan utama untuk merujuk ke dokter kardiologi anak. Sebagian besar bising ini merupakan bising inosen dan tidak berhubungan dengan kelainan organik atau kelainan struktural jantung. ${ }^{1-5}$ Bising inosen tidak bersifat 
patologis tetapi sering disalahartikan sebagai bising organik. Untuk mendiagnosis bising inosen diperlukan pengalaman dan ketrampilan sehingga banyak pemeriksaan penunjang yang sebenarnya dapat dihindari seperti EKG, foto torak serta pemeriksaan baku emas ekokadiografi. ${ }^{1,2,6,7}$

Beberapa penelitian menunjukkan bahwa dokter kardiologi anak yang berpengalaman dapat mendiagnosis bising inosen secara klinis tanpa bantuan pemeriksaan penunjang dengan ketepatan sebesar 96$98 \% .^{2,8-11}$ Shry, dkk ${ }^{12}$ menyatakan perbandingan antara pemeriksaan fisis dan ekokardiografi oleh ahli kardiologi anak mempunyai sensitivitas sebesar $100 \%$, spesifisitas sebesar $67 \%$, nilai prediksi positif sebesar 30\% dan nilai prediksi negatif sebesar 100\%. Haney, dkk ${ }^{13}$ melaporkan sensitivitas dan spesifisitas pemeriksaan fisis oleh dokter spesialis anak $82 \%$ dan $24 \%$, yang dengan pelatihan pengenalan bising jantung anak meningkat masing-masing menjadi 87\% dan 98\%. Mahnke, dkk ${ }^{14}$ melaporkan bahwa kemampuan pengenalan bising jantung anak oleh residen sangat buruk dan perlu pelatihan khusus untuk meningkatkan kemampuan pengenalan bising jantung.

Departemen Ilmu Kesehatan Anak FKUI-RSCM sampai saat ini belum mempunyai data sensitifitas dan spesifisitas pemeriksaan fisis untuk bising jantung pada anak yang dicurigai sebagai bising inosen dibandingkan pemeriksaan ekokardiografi sebagai baku emas. Tujuan penelitian ini untuk membandingkan ketajaman pemeriksaan fisis oleh seorang peserta program pendidikan dokter spesialis anak 1 (peserta PPDS anak 1) yang telah mendapat pelatihan khusus pengenalan dan diagnosis bising jantung dengan pemeriksaan ekokardiografi yang digunakan sebagai baku emas.

\section{Metoda Penelitian}

Desain penelitian adalah uji diagnostik. Pelatihan khusus pengenalan bising jantung anak pada peneliti dilakukan selama \pm 1 bulan (Juli 2005) oleh dokter kardiologi anak sebelum penelitian dimulai. Subyek penelitian adalah pasien anak usia 1 bulan -12 tahun dengan bising jantung derajat 1-3/6 dan belum pernah didiagnosis kelainan jantung dan tanpa sianosis, yang datang ke poliklinik anak umum Departemen Ilmu Kesehatan Anak FKUI-RSCM. Penelitian dilakukan selama 3 bulan, yaitu sejak 1 Agustus sampai 31
Oktober 2005. Hasil pemeriksaan fisis kemudian dikonfirmasi dengan pemeriksaan ekokardiografi sebagai baku emas.

\section{Hasil}

Bising jantung ditemukan pada 39 dari 641 pasien yang diperiksa. Tiga puluh lima pasien diduga mempunyai bising inosen dan 4 pasien diduga memiliki bising patologis. Prevalensi anak dengan bising jantung yang diperkirakan bising inosen adalah 35/641 $(5,4 \%)$ atau 5 dari 100 pasien yang diperiksa terdengar bising yang diperkirakan bising inosen. Bising jantung terbanyak ditemukan pada pasien berusia 3-7 tahun dan jenis kelamin laki-laki (Tabel 1).

Tabel 1. Karakteristik 39 pasien dengan bising jantung di poli klinik umum Departemen IKA FKUI-RSCM (1 Agustus 2005-31 Oktober 2005).

\begin{tabular}{lc}
\hline Karakteristik pasien & Jumlah \\
\hline Umur (tahun) & \\
$\quad 1$ & 4 \\
$\quad 3$ & 6 \\
$7>$ & 22 \\
& \\
Jenis kelamin & \\
Laki-laki & 22 \\
Perempuan & 17 \\
\hline
\end{tabular}

Konfirmasi pemeriksaan fisik dengan pemeriksaan baku emas ekokardiografi pada 35 pasien yang diduga memiliki bising inosen ternyata 3 pasien menunjukkan bising patologis, yaitu bising sistolik yang disebabkan oleh defek septum atrium (DSA). Empat pasien yang diduga memiliki bising patologis, hanya 3 yang ternyata benar memiliki bising patologis setelah dikonfirmasi dengan ekokardiografi. Satu pasien, yaitu laki-laki berusia 12 tahun dengan bising Still pada awalnya diduga DSA, ternyata tidak dijumpai kelainan pada jantung setelah dikonfirmasi dengan ekokardiografi. (Tabel 2)

Sensitivitas pemeriksaan fisis terhadap bising inosen: 32 adalah $(32+1) \times 100 \%=97 \%$ dan spesifisitas $3:(3+3) \times 100 \%=50 \%$. Nilai duga positif adalah $32:(32+3) \times 100 \%=91 \%$, sedangkan nilai duga negatif adalah $3:(1+3) \times 100 \%=75 \%$. Rasio kemungkinan positif $32:(32+1):(3:(3+3)=1,94$ 
Tabel 2. Hasil ekokardiografi pada 39 pasien yang mempunyai bising berdasarkan pemeriksaan fisis.

\begin{tabular}{|c|c|c|c|c|}
\hline & \multicolumn{3}{|c|}{ Ekokardiografi (kelainan anatomis) } & \multirow[t]{2}{*}{$\mathrm{n}$} \\
\hline & & Tidak ada & Ada & \\
\hline \multicolumn{5}{|l|}{ Pemeriksaan } \\
\hline \multirow[t]{3}{*}{ fisis (Bising) } & Inosen & 32 & 3 & 35 \\
\hline & Patologis & 1 & 3 & 4 \\
\hline & $\mathrm{n}$ & 33 & 6 & 39 \\
\hline
\end{tabular}

dan rasio kemungkinan negatif $1:(32+1): 3:(3+3)$ $=0,6$.

Jumlah bising yang diduga sebagai bising inosen dalam penelitian ini adalah 37 bising dari 35 pasien yaitu, bising Still (11) dan venous hum (26). Hal ini dapat terjadi karena pada 3 pasien terdengar 2 jenis bising yaitu bising Still dan venous hum. Pemeriksaan ekokardiografi pada ketiganya menunjukkan hasil yang sesuai dengan bising inosen. Tiga pasien yang diduga bising patologis terdiri dari, 2 pasien bising kontinu (dengan ekokardiografi sesuai dengan DAP) dan 1 pasien bising pansistolik (dengan ekokardiografi sesuai DSV)

\section{Diskusi}

Pada dewasa, bising sistolik fisiologis atau inosen mudah dibedakan dengan bising sistolik patologis karena kaitannya dengan kelainan klinis sangat jelas. ${ }^{15}$ Sedangkan pada anak, bising sistolik fisiologis atau bising inosen prevalen cenderung berubah-ubah tergantung umur. ${ }^{16} \mathrm{Du} \mathrm{dkk^{17 }}$ melaporkan pada neonatus, prevalen bising inosen hanya $16 \%$. Pada bayi mencapai $60 \%$ dan pada anak usia sekolah mencapai $75-90 \%$ dari populasi, dengan prevalensi terbesar pada usia 3-7 tahun. ${ }^{6,17,18}$ Bergman, $\mathrm{dkk}^{16}$ melaporkan penelitian pada 93 anak sekolah dengan bising jantung, 18 anak (19\%) di antaranya mengalami bising patologis, dan 75 anak (81\%) tidak ada penyakit jantung yang mendasari.

Pada penelitian ini, seperti yang terlihat pada Tabel 1, anak usia 3-7 tahun merupakan prevalensi terbesar mengalami bising yang diduga inosen, yaitu 22 anak atau $62 \%$ dari seluruh anak yang diduga mengalami bising inosen, sedangkan usia 0-1 tahun menempati proporsi terkecil.
Penelitian oleh Haney, dkk ${ }^{13}$ menunjukkan bahwa pemeriksaan bising jantung yang dilakukan oleh dokter ahli kardiologi anak mencapai sensitivitas (92\%-96\%) dan spesifisitas (82\%-85\%). Advani, dkk ${ }^{19}$ menemukan pasien yang didiagnosis bising inosen oleh dokter kardiologi anak tidak ada yang mengalami kelainan jantung. Sedangkan sensitivitas pemeriksaan oleh dokter anak umum adalah suboptimal. Mahnke, $\mathrm{dkk}^{14}$ melaporkan bahwa residen yang telah mengikuti pelatihan untuk mendiagnosis bising inosen ternyata masih rendah dengan kemampuan 53\% $13 \%$. Hal ini sama dengan yang ditemukan oleh Gaskin dkk. ${ }^{11}$ Kemampuan seorang dokter kardiologi anak dalam mendeteksi bising inosen secara klinis sangat membantu menghemat biaya. Yi, dkk ${ }^{20}$ menyatakan bahwa pemeriksaan oleh dokter kardiologi anak secara klinis tanpa pemeriksaan ekokardiografi akan meningkatkan cost-effectiveness. Satu pasien berusia 12 tahun pada awalnya diduga mengalami DSA, dengan bising sistolik grade II-III/6 dan asimtomatis, setelah konfirmasi dengan ekokardiografi ternyata tidak ditemukan kelainan anatomis.

Hasil penelitian oleh beberapa peneliti menunjukkan bahwa kesalahan menduga suatu bising inosen sebagai bising patologis dapat terjadi. Smythe $\mathrm{dkk}^{2}$ melaporkan dari 161 anak usia 1 bulan-17 tahun (usia rata-rata 3,2 tahun) yang diperiksa oleh ahli kardiologi anak, 109 pasien diduga mempunyai bising inosen, 2 diantaranya mengalami bising patologis (1 dengan DSV kecil, 1 dengan DSA kecil); dari 46 pasien dengan bising patologis, 3 pasien ternyata bising inosen. Penelitian ini mempunyai sensitivitas 96\% dan spesifisitas 95\%. Penelitian Newburger, $\mathrm{dkk}^{8}$ pada 280 anak berusia 1 bulan-18 tahun dengan bising jantung, yaitu 142 anak diduga bising inosen, ternyata setelah ekokardiografi ditemukan, 3 anak menderita mitral-valve prolaps, 2 anak dengan kemungkinan kardiomiopati, dan 3 anak yang diduga mengalami bising patologis pada pengamatan selanjutnya ternyata merupakan bising inosen, hanya 4 anak yang pada akhirnya mengalami sakit jantung definitif.

Mahnke, $\mathrm{dkk}^{14}$ melaporkan bahwa kemampuan residen dalam pengenalan bising jantung anak sangat buruk. Haney, dkk ${ }^{13}$ melaporkan sensitivitas dan spesifisitas oleh dokter spesialis anak adalah $82 \%$ dan $24 \%$, dan setelah mendapat pelatihan khusus meningkat menjadi $87 \%$ dan $98 \%$. Peneliti dalam penelitian ini adalah PPDS Anak I yang telah 
mengikuti pelatihan khusus mengenai pengenalan bising jantung anak, dan pemeriksaan fisis yang dilakukannya untuk membedakan bising inosen dan bising patologis cukup dapat diandalkan. Sensitivitas penelitian ini mencapai $97 \%$, sedangkan spesifisitasnya mencapai $50 \%$, hal ini dapat dilihat pada Tabel 2. Nilai duga positif atau perkiraan benar bahwa hasil pemeriksaan fisis akan menunjukkan bising yang terdengar adalah benar bising inosen pada penelitian ini adalah 91\%, sedangkan nilai duga negatif adalah $75 \%$. Rasio kemungkinan untuk hasil pemeriksaan fisis positif sesuai dengan bising inosen adalah 1,94 sedangkan rasio kemungkinan untuk hasil pemeriksaan fisis negatif adalah 0,6 , menunjukkan hasil uji sedang.

Pada penelitian ini semua bising yang diperkirakan sebagai bising inosen adalah bising sistolik, yaitu 11 bising Still dan 26 bising venous hum yang merupakan bising sistolik kontinyu. Kepustakaan menyebutkan bahwa sebagian besar bising inosen adalah bising sistolik, seperti yang dilaporkan oleh Tavel dan Still, yaitu sebanyak 70\% - 90\% bising inosen adalah bising sistolik. ${ }^{21}$ Bising sistolik ini banyak dijumpai pada anak berusia sekitar 2-7 tahun, walaupun kadang-kadang dapat dijumpai pada bayi dan anak usia kurang dari 2 tahun. ${ }^{3,5,7}$ Bising Still sering menghilang pada saat pubertas dan pada beberapa kasus dapat menetap hingga dewasa. ${ }^{5}$

\section{Kesimpulan}

1. Sensitivitas dan spesitifitas diagnosis bising inosen berdasarkan pemeriksaan fisis dibandingkan pemeriksaan ekokardiografi masing-masing adalah 97\% dan 50\%.

2. Nilai duga positif diagnosis bising inosen berdasarkan pemeriksaan fisis dibandingkan pemeriksaan ekokardiografi adalah 91\% dan nilai duga negatif 75\%.

3. Rasio kemungkinan untuk hasil positif sesuai dengan bising inosen adalah 1,94 sedangkan rasio kemungkinan untuk hasil negatif adalah 0,6. Hal ini menunjukkan bahwa pemeriksaan fisis cukup bisa diandalkan untuk menentukan bising inosen dan bising patologis.

4. Pemeriksaan fisis oleh dokter anak atau residen yang telah mendapat pelatihan khusus mendengar bising jantung dan mengenal macam-macam jenis bising jantung cukup dapat dipercaya sehingga dapat menurunkan keharusan pemeriksaan ekokardiografi yang mahal.

\section{Daftar Pustaka}

1. Gessner IH. Evaluation of the infant and child with a heart murmur. Dalam: Victorica BE, Gessner IH, penyunting. Pediatric cardiology: a problem oriented approach. Philadelphia: WB Saunders;1993. h.131-46.

2. Smythe JF, Teixeria OHP, Vlad P, Demers PP, Feldman W. Initial evaluation of heart murmur: are laboratory tests necessary. Pediatrics 1990; 86:497-500.

3. Pelech AN. The cardiac murmur. Pediatric Clinic of North America 1998;45:107-22. Didapat dari: / das / journal / view h/17104660 / N /10058318?ja =98006 \& $\mathrm{PAGE}=1 . \mathrm{html} \& \mathrm{ANCHOR}=$ top \&source $=\mathrm{MI}$

4. Latief A, Tumbelaka AR, Matondang CS, Chair I, Bisanto J, Abdoerrachman MH dkk. Dalam: Matondang CS, Wahidiyat I, Sastroasmoro, penyunting. Diagnosis fisis pada anak. Jakarta: Sagung Seto; 2000. h. 83-7.

5. Danford DA, McNamara DG. Innocent murmur and heart sounds. Dalam: Garson A, Bricker JT, Fisher DJ, Neish SR, penyunting. The science and practice of pediatric cardiology. Edisi-2. Pennsylvania: Wiliams \& Wilkins; 1998. h. 2203-12.

6. Sastroasmoro S, Sampurno SI. Anamnesis dan pemeriksaan fisis. Dalam: Sastroasmoro S, Madiyono $\mathrm{B}$, penyunting. Buku ajar kardiologi anak. Jakarta: Binarupa Aksara; 1994. h. 24-28

7. Park MK. Pediatric cardiology for practitioners. St. Louis: Mosby; 1996. h. 31-3.

8. Newburger JW, Rosenthal A, Williams RG. Noninvasive tests in the initial evaluation of heart murmurs in children. N Engl J Med 1983;308:61-4

9. Advani N. Parents and children's perception of innocent murmur. Thesis. Melbourne: Department of Cardiology, Royal Children's Hospital-University of Melbourne, 1998.

10. Danford DA, Salaymeh KJ, Martin AB, Fletcher SE, Gumbiner. Pulmonary stenosis: Defect-specific diagnostic accuracy of heart murmur in children. J Pediatr 1999; 134:76-81.

11. Gaskin PRA, Owens SE, Talner NS, Sanders SP,Li JS. Clinical auscultation skills in pediatric residents. Pediatrics 2000; 105:1184-7.

12. Shry EA, Smithrs MA, Mascette MA. Auscultation versus echocardiography in a healthy population with precordial murmur. Am J Cardiol 2001;87:1428-30. Didapat dari: http://www.mdconsult.com Bookmark / das/journal/view/17104660/N/12075450?ja= 63315\& PAGE $=1$. html\&ANCHOR=top\&source.

13. Haney I, Ipp M, Feldman W, McCrindle Bw. Accuracy 
of clinical assessment of heart murmurs by office based (general practice) paediatricians. Arch Dis Child 1999; 81:409-12.

14. Mahnke CM, Nowalk A, Hofkosh D, Zuberbuhler JR, Law YM. Comparison of two educational interventions on pediatric resident auscultation skills. Pediatrics 2004; 113:1331-5.

15. Shub C. Echocardiography or auscultation?Can Fam Physician 2003; 49:163-7.

16. Bergman AB, Stemm SJ. The morbidity of cardiac nondisease in shoolchildren. N Engl J Med 1967; 276: 1008-13.

17. Du ZD, Roguin N, Barak M. Clinical and echocardiographic evaluation of neonates with heart murmurs. Acta Paediatr. 1997;86:752-6. abstrak. Didapat dari: /das/ journal/view/17104660/N/9893274? source=MI.
18. Bernstein D. The cardiovascular system. Dalam: Behrman RE, Kliegman RM, Arvin AM, penyunting, Nelson textbook of pediatrics. Edisi ke-15. Philadelphia: WB Saunders; 1996. h. 1269.

19. Advani N, Menahem S, Wilkinson JL. The diagnosis of innocent murmurs in childhood. Cardiol Young. 2000; 10:340-2.

20. Yi MS, Kimball TR, Tsevat J, Mrus JM, Kotagal UR. Evaluation of heart murmurs in children: cost-effectiveness and practical implications. J Pediatr 2002; 141 : 504-11.

21. Veasy LG. Innocent heart murmurs in children. Dalam: Pine JW, penyunting. Moss and Adams Heart disease in infants, children and adolescents including the fetus and young adult. Edisi ke-5, Baltimore: Williams \& Wilkins; 1995. h. 650-3. 